\title{
FOOD PRICES, TAXES, AND OBESITY IN CANADA AND ITS IMPLICATIONS FOR FOOD TAXATION
}

\author{
Stephen J. Clark, Ludwig O. Dittrich, Stephen M. Law, \\ Dana Stará, Miroslav Barták
}

\section{Introduction}

An important health financing issue facing Canada and other OECD countries (OECD, 2017) are the health consequences of obesity. Statistics Canada (2014) reports that 51.6\% of adult Canadians were overweight or obese in 2009 compared to $53.6 \%$ in 2013. The proportion of Canadians who are overweight differs by sex, with $59.2 \%$ of Canadian males overweight in 2009 compared to $62 \%$ in 2013 and $43.9 \%$ of females overweight in 2009 compared to $45.1 \%$ in 2013 . These increases have led to calls for policies to control obesity (see Clark et al., 2014).

These rates of obesity are based on the body mass index (BMI) which is the ratio of weight (in kilograms) to the square of height (in meters). Cranfield (2007) uses the Canadian Community Heath Survey (CCHS) to examine the determinants of the body mass index (BMI) of Canadians. Unfortunately, there is insufficient information in the CCHS data on the dietary behaviour of respondents so that the way in which diets influence BMI cannot be directly studied using that dataset. This lack of information on dietary choices is a common feature of studies that measure the BMI of individuals. For example, the BMI data used by Goldman, Lakdawalla, and Zheng (2009) also does not include observations of the diets of individuals.

One solution to this problem is to include the prices of dietary elements in place of quantities since, while quantities may not have been observed, prices typically are. Nutrient prices are included in the BMI studies of Goldman, Lakdawalla and Zheng (2009) and Clark et al. (2014) whereas food group prices are included in studies by Chou, Grossman and Saffer (2004), Boizot-Szantai and Fabrice (2005) and Strum and Datar (2005) and (2008). In this study we discuss some considerations for the determination of the appropriate set of prices to use within a study of obesity. We compare the use of food-group-prices to nutrient-prices. By far the most popular approach in this area of research is the use of food group prices (e.g., Chou, Grossman, \& Saffer, 2004; BoizotSzantai \& Fabrice, 2005; Strum \& Datar, 2005; 2008; along with Beatty \& LaFrance, 2005; Chouinard et al., 2005; Smed, Jensen, \& Denver, 2007; Allais, Bertail, \& Nichele, 2010). Fewer studies use nutrient prices (Goldman, Lakdawala, \& Zheng, 2009; Clark et al., 2014).

A theoretical model developed by Chen et al. (2004) explores the relationship between nutrients and hypertension. Their model clearly demonstrates that if nutrients are a determinant of a specific health outcome (hypertension, in their case) then nutrient prices are the most appropriate set of prices to use. In their empirical model they do not use nutrient prices but food group prices, proposing that their estimated model is a "reduced form" model.

We assert that Chen et al. (2004) are correct in their interpretation of their model and that food group prices included in obesity studies lead to estimates of a reduced form model and nutrient prices lead to estimates of a "structural" model. Given this interpretation, food group prices can be used to estimate the model if one is interested in a reduced form model of the determinants of obesity and nutrient prices should be used if one is interested in estimating a structural model of obesity that is more amenable to interpretation for policy purposes. The distinction is critical since reduced form models allow for the estimation of other nonprice variables in the system to make sure there is not an "omitted" variable problem but they are less useful for policy purposes unless some additional approach is grafted on to the study for the purpose of uncovering the structural parameters. Parameter estimates from the use 
of food group prices should not be used to make judgements concerning the health impacts of taxes on consumption of foods from many of the food groups because too many factors are confounded in the reduced form model relating those food group prices to the underlying nutrients. We provide some examples of this shortcoming of the food group approach below.

The use of nutrient prices is a more promising line of research in this area since this approach captures the prices of the specific nutrients thought to be causing undesired health risks by nutritionists. The difficulty with nutrient prices is that they are not typically collected by statistical reporting institutions and are not directly observable. Nutrient prices need to be constructed from existing data bases and linked to the observations on expenditures and BMI. The goal of the study is to introduce new nutrient price model and shows its superiority of food group model based on Canadian data.

This study is organized as follows. The next section reviews food policy in Canada, specifically supply management regimes and the taxation of food, and the ways in which the structure of these policies reflects consideration of health outcomes, if at all. The following section reviews the literature on prices of food and nutrients in studies of obesity and other health outcomes. This is followed by a discussion of the data and methods. The penultimate section discusses the results and the final section provides a discussion of policy implications, relevance of nutrient taxation model for other countries and conclusions.

\section{Food Price and Tax Policies in Canada and Their Relationship to Obesity}

While there are no food policies in Canada that explicitly target obesity in Canada, there are several policies in place that influence the relative prices of various foods in relation to other foods. Traditionally, Provincial and Federal HST and GST taxes in Canada have exempted many foods. However, there are three major areas of food taxes that are common to many provincial and federal taxes in Canada that may influence obesity: (1) Taxes on restaurant food; (2) Taxes on convenience food; and (3) "Taxes" on food related to supplymanaged food industries.

\subsection{Taxes on Restaurant Food}

Restaurant food has been subject to federal taxes (GST) and provincial taxes (PST or the provincial component of HST) in Canada. In the obesity literature, these taxes are roughly comparable to taxes on "fast food" in the literature. Therefore, in as much as "restaurant" food lines up to a food group called "fast food", Canada has had an obesity tax for a long time.

\subsection{Taxes on Convenience Foods}

Another obesity tax that is often advocated in related literature is a tax on "junk" food, high fat or high caloric food that is thought to contribute to obesity. While there are no food taxes in Canada that explicitly target "junk" food for taxing, HST or PST and GST are applied to further-processed foods, or "convenience" foods. These taxes are unevenly and inconsistently applied if they are viewed from the perspective of taxes whose purpose is to control obesity. While this category does correspond to several foods that are commonly considered to be "junk" foods (e.g., potato chips), other high fat, high sugar foods are untaxed (e.g., ice cream) and foods which are intended to be obesity-reducing (such as Weight Watchers $®$ frozen food dinners) are also taxed. Furthermore, the convenience food taxes are inconsistently applied to specific foods. For example, individual cookies are taxed, whereas cookies purchased in bags in quantities greater than six cookies are not (as long as they are not individually wrapped).

\subsection{Supply Management Industry Taxes}

The final category of food price increases (or "taxes") in Canada are those imposed on consumers by the supply managed industries. These include dairy, poultry, and egg products. For a discussion of the relative size of these implicit taxes, see Cardwell, Lawley and Xiang (2015). In the case of poultry and egg products, it is debatable whether increasing their price will decrease obesity, since these products are often singled out as products that contribute to a healthier diet by nutritionists, especially poultry products. To the extent that poultry and eggs are "good" foods, the implicit taxes from supply management in these industries might be considered obesogenic rather than leptogenic. Price increases from supply management in the dairy sector are a unique case from the point of view of obesity taxes. Dairy supply management 
has two impacts on consumers. The first is the usual tax on consumers from raising the retail price of dairy products to consumers. For these taxes, since many dairy products are high fat and therefore lead to an obese outcome, dairy taxes promote a less obese society. The second is the peculiar way dairy quota is allocated on the basis of the fat content of milk. This allocation system lowers the amount of dairy fat that enters the system. None of these taxes are explicitly imposed to promote healthy eating on the part of consumers. Therefore, they do not necessarily target the nutrients responsible for causing obesity in Canada. Clark and Dittrich (2010) argue that nutrient taxes (e.g., taxes on the fat content of food) better target the problem than do food group taxes (i.e., taxes on food composites) and therefore nutrient taxes are more effective as a means to promote less obesity. All of the taxes in Canada, with the exception of the allocation of milk quotas by fat content, are food group taxes. The problem of what prices are appropriate for obesity studies is discussed in the next section.

Tab. 1 summarizes food taxes on convenience foods and restaurant foods by province in Canada together with the average BMI by province. The table suggests that there is no consistent story that can be told that relates the level of the sales taxes on convenience foods and restaurant foods in Canada to obesity. For example, Alberta has the lowest rate of taxes on convenience and restaurant foods in Canada and Albertans have the lowest average BMI in the country, while Atlantic Canada has the highest taxes on restaurant and convenience foods and Atlantic Canadians are among the highest average BMI in the country. This indicates that there could be considerable confounding from simultaneous positive and negative effects appearing in the raw correlations of restaurant and convenience food taxes with the BMI of Canadians. In Ontario restaurants meals are exempt from provincial tax if expenditure are less than 4 CND.

\section{Prices in Obesity Studies}

The empirical literature in this area is primarily composed of studies which have concentrated on estimating the reduced form relationship between food group prices and an obesogenic (that is, "obesity-increasing") nutrient or dietary element, such as fat, carbohydrates, or calories. The most common approach (Huang, 1996; Beatty \& LaFrance, 2005; Chouinard et al., 2005; Smed, Jensen, \& Denver, 2007; Allais, Bertail, \& Nichele, 2010) is to relate the reduced for the obesogenic nutrient to overall demand for the food group product by combining the average nutrient content of food in fixed proportions with the overall quantity demanded of the food group to proceed from a reduced form model of food demand to a structural model of nutrient demand.

\begin{tabular}{l|c|c|c|c} 
Tab. 1: & $\begin{array}{c}\text { Average BMI (2010) and tax rates for restaurant meals and convenience foods } \\
\text { in Canada (as of May 2015) }\end{array}$ \\
\hline Province & Provincial Tax & Federal Tax & Combined Tax & $\begin{array}{c}\text { Average BMI } \\
\text { in 2010 }\end{array}$ \\
\hline Alberta & n.a. & $5 \%$ & $5 \%$ & 25.987 \\
\hline Saskatchewan & n.a. & $5 \%$ & $5 \%$ & 26.862 \\
\hline British Columbia & $7 \%$ & $5 \%$ & $12 \%$ & 27.411 \\
\hline Manitoba & $8 \%$ & $5 \%$ & $13 \%$ & 27.361 \\
\hline New Brunswick & $8 \%$ & $5 \%$ & $13 \%$ & 27.657 \\
\hline Newfoundland \&Labrador & $8 \%$ & $5 \%$ & $13 \%$ & 27.839 \\
\hline Ontario & $8 \%$ & $5 \%$ & $13 \%$ & 26.746 \\
\hline Prince Edward Island & $9 \%$ & $5 \%$ & $14 \%$ & 26.984 \\
\hline Quebec & $9.975 \%$ & $5 \%$ & $14.975 \%$ & 26.001 \\
\hline Nova Scotia & $10 \%$ & $5 \%$ & $15 \%$ & 27.238 \\
\hline
\end{tabular}


This approach has three advantages. First, demand elasticities from food demand systems can be used to derive the response of consumption of the obesogenic nutrient to changes in food group prices. Second, given the fixed proportions assumption, a demand elasticity of the obesogenic (or combinations of obesogenic) nutrient prices can also be established. The fixed proportions assumption allows an analysis of either the effect of changes to a food group price or nutrient price on consumption, while empirically using only food group prices to estimate the food demand system. Third, estimates of relationships can be established using existing demand system estimates which have been intensively studied and so excellent estimates of demand elasticities are available.

There are three problems with this approach. First, the assumption of fixed proportions between the overall elasticity and the obesogenic nutrient that allows for the construction of a structural elasticity from a reduced form to a structural elasticity is a maintained hypothesis that may not be valid. This approach allows for acrossgroup substitutions of obesogenic nutrients but does not allow for within-group substitutions of nutrients. Clark and Dittrich (2010) observe that food groups have a large number of elementary goods and that with changes in price substitutions of nutrients within groups commonly take place.

Second, the food demand systems typically estimated are based on at-home food expenditure data. This means a large category of food expenditures that may affect obesity is not captured in the analysis. This category comprises $50 \%$ of food expenditures in the US in 2014 (United States Department of Agriculture). The assumption that an at-home dairy elasticity adequately captures the awayfrom-home dairy elasticity seems dubious at best since the dietary habits of consumers with respect to at-home and away-from-home food are probably much different. For example, food away-from-home may be considered a "treat" where typical at-home rules of dietary discipline do not apply. Also, consumers have less control of nutrient intake from away-from-home food than at-home food. Furthermore, even if a category in food demand systems estimated an away-from-home food demand elasticity, this could not be combined with nutrient data, since nutrient data are developed using athome food groups and not away-from-home food groups. For example, while there are data on aggregate fat levels in the food group "dairy" for at-home consumption, there are no data on fat proportions in the corresponding away-fromhome food group.

Third, food demand systems inform us about the food purchases by consumers, but they may not tell us very much about what is actually eaten and this is what ultimately interests us for a study of obesity. In others words, estimating elasticities of nutrients purchased by consumers, which is what these studies actually do, may tell us little about obesity. Kantor et al. (1997) estimate that $26 \%$ of food purchased by Americans is not consumed but enters the economy as food waste. Encouraging consumers to eat more fresh fruits and vegetables as a way to reduce obesity may not be as effective as hypothesized if $32 \%$ of purchased fresh fruits and vegetables are not consumed but wasted (Kantor et al., 1997). Furthermore, food waste for fresh fruits and vegetables may be much higher at the margin. Therefore, combining an at-home fruits and vegetables elasticity of demand in fixed proportions with the average nutrient content in fruits and vegetables probably overestimates the impact on obesity of a particular nutrient.

Clark and Levedahl (2006) and Xu (2010) show how the problem of fixed proportions can be overcome empirically by regressing nutrients on food group prices. These estimations generate a set of elasticities of nutrient response to food group prices. Variable proportions allows for within-group substitutions of nutrients and the model does not use food expenditure data to generate elasticities of nutrients to food group prices and so nutrient quantities include both food at-home and awayfrom-home food groups.

While the variable proportions approach seems promising, it has not performed particularly well empirically in earlier studies. For example, Xu (2010) does not find substantial statistical significance from estimating fat, carbohydrate, and calorie elasticity estimates from food group prices using US data. While Clark and Levedahl (2006) do find a statistically significant relationship between fat and meat prices, the meat group is not particularly striking as a major source of fat causing obesity. Neither of these studies includes nutrient prices in the analysis. Also, these estimates only include elasticities of food disappearance of nutrients 
to prices, and not estimates of nutrients eaten, and therefore waste is not considered. Beatty (2007) uses an entropy approach to generate shadow prices of nutrients but the estimates are still based on only food at-home demand elasticities.

Another popular approach is to measure the health outcome directly rather than indirectly through changes in some obesogenic nutrient, such as fat from food purchased for at-home consumption. For example, there are several studies that relate the BMI of populations to various socio-economic variables including prices of relevant goods (e.g., Chou et al., 2004; Boizot-Szantai, \& Fabrice, 2005; Strum \& Datar, 2005; 2008; Auld \& Powell, 2009; Goldman, Lakdawalla, \& Zheng, 2009; Clark, et al., 2014). Chen et al. (2002) use similar methods to examine blood pressure.

A common feature of the BMl data used in these studies is that information on nutrient intake is unavailable, and so prices are included in place of quantities. A basic question of these studies, and seldom discussed, is what prices ought to be included in BMI studies? Two types of prices are examined in this study: nutrient prices and food group prices. Chen et al. (2002) demonstrate that the use of food group prices results in estimation of the reduced form model and nutrient prices estimate the structural model. Which prices best capture nutrients in diets as they relate to obesity is discussed in Clark and Dittrich (2010) who argue that nutrient prices better capture the effects of taxes to control obesity than food group prices. Beatty (2007) implies that the appropriate price is a nutrient price in his study to develop shadow values of nutrients. Chen et al. (2002) develop a theoretical model in which blood pressure is the health outcome and conclude that nutrient prices are appropriate to estimate the structural model which in turn identifies parameters that can be used from a policy perspective. The food price model is a reduced form model from which the coefficient estimates are subject to confounding of nutrient effects within and across food groups. Chen et al. (2002) call nutrient prices "implicit" prices in their model, and this term highlights the fact that nutrient prices are not readily available. This could be one reason why they estimate a model including food group prices rather than a model including nutrient prices. Goldman, Lakdawalla and Zheng (2009) show how data on food expenditures, prices for food groups, and food disappearance of nutrients can be used to generate nutrient prices (for at-home food consumption). In this study we estimate two models, one including nutrient prices and the other including food group prices, to compare the empirical performance of the two approaches.

\section{Methods and Data}

The methodology is based on the previous work of Clark et al. (2014). Data on BMI of Canadian adults (eighteen years of age or older), socio-economic data and other data related to individual health status of individuals is available from the personal characteristics data that comes from Canadian Community Health Survey (CCHS) (Statistics Canada, 2012b) and the personal health indicators of Canadians (Statistics Canada, 2012c). The CCHS is an annual survey containing information on health status, health care utilization and health determinants for the Canadian population greater than twelve years old. The variables included in this study from the CCHS survey included BMI, income, education, age, gender, household size and a variety of health status indicators (see Clark et al., 2014, pp. 252-253).

Clark et al. (2014) are citing Goldman, Lakdawalla and Zheng (2009) who develop a formula that shows how food disappearance data on nutrient intake can be combined with food expenditure data to develop a proxy for a nutrient price. Specifically, their formula is

$$
\mathrm{NP}_{l i}=\frac{1}{\sum \mathrm{S}_{i j} \times \frac{N_{l}}{\mathrm{CPI}_{i j}}}
$$

where $N P_{l i}$ is nutrient price of the $t^{\text {th }}$ nutrient (fat, carbohydrates, protein) of the $i^{\text {th }}$ province, (Newfoundland, Prince Edward Island, Nova Scotia, New Brunswick, Quebec, Ontario, Manitoba, Saskatchewan, Alberta, British Columbia and the territories - Nunavut, Yukon and the Northwest Territory - included in a "province" called North Canada), $S_{i j}$ is the expenditure share of the $j^{\text {th }}$ food group (milk; cheese; eggs; fruit; cereals; vegetables; beef; pork; poultry; fish; sugar and sweeteners; fats and oils; and coffee and tea) in the $i^{\text {th }}$ Province, expenditure share is expenditure share of food group $j$ in Province $i$ per capita per day (Statistics Canada, 2012d; 2012e), N 
is nutrient food disappearance for the $I^{\text {th }}$ nutrient per capita per day (Statistics Canada, 2012c) and $C P I_{i j}$ is consumer price index for food group $j$ in Province $i$ (Statistics Canada, 2012f). In the food group price model, the $C P I_{i j}$ of Province $j$ for the following food groups are used: dairy, eggs, fruits and vegetables, eggs, cereals, red meats, poultry, fish, sugar and sweeteners, fats and oils and restaurant food (Statistics Canada, 2012f). (see Clark et al., 2014, p. 252).

Note that at-home food group expenditure share data are used to generate nutrient prices. This means that prices are generated for the at-home category of nutrient prices and do not include the away-from-home share of the nutrient in food. This means that measures of nutrient prices used in this study are dependent upon the food pyramid aggregation system.

All of the data are for the year of 2010, except the data on nutrient food disappearance (Statistics Canada, 2012c), which is not available for 2010. We use the 2009 nutrient food disappearance data in Canada as a proxy for 2010. While it is not possible to know how closely the 2009 data proxies for 2010 data, data from The Center for Nutrition and Public Policy in the US indicate that nutrient food disappearance per capita changes very slowly. After deleting the observations that were recorded as unknown, not applicable, refused to answer or not stated, the sample consists of responses from 39,805 Canadians eighteen years or older (see Clark et al., 2014).

Food expenditure data and CPI data were not available for the North region, and so we use a population-weighted price to determine the $\mathrm{CPI}$ in North Canada and regard the average Canada expenditure share as the expenditure share in North Canada. Since so few of the responders to the CCHS were from the North region, the results did not change appreciably when Northern region's responses were excluded from consideration. These results are not shown, but available on request. The data on prices generated from equation (1) are combined with BMI and other socio-economic and health status data to estimate the BMI equations (see Clark et al., 2014, p. 252). The empirical model estimated is:

$$
\mathrm{BMI}_{k i}=\alpha+\beta^{\prime} \mathrm{PC}_{k i}+\gamma^{\prime} N P_{i}+\varepsilon_{k i}
$$

where $B M I_{k i}$ is body mass index of individual $k$ in Province $i$ (Statistics Canada, 2012b),
$P C_{k i}$ is a vector of personal characteristics data of individual $k$ in Province $i, P_{i}$ is a vector of nutrient prices or a vector of food group prices in Province $i$ and $\beta$ and $\gamma$ are vectors of parameters to be estimated (Clark et al., 2014).

\section{Results and Obesity Tax Assessment}

The model is estimated in linear natural logarithm form, meaning that parameter estimates are elasticities. Tab. 2 presents Ordinary Least Square (OLS) estimates of the reduced form food group price model (elasticity estimates in the 2 nd column and t-values in the 3rd column) and the structural nutrient price model (elasticity estimates in the fourth column and $t$-values in the fifth column) resulting from estimating the OLS estimates of the BMI of Canadians in 2010. Obesogenic nutrient prices and food group prices have negative coefficients and indicate that a tax will lower the $\mathrm{BMI}$ of Canadians and leptogenic nutrient prices and food group prices have positive coefficients and indicate that a subsidy will lower the BMI of Canadians.

As appropriate devices for ensuring other parameter estimates in the model are not biased, both models give similar results. The elasticity estimates of all of the variables included in each model except for price variables are quite similar, except perhaps the household size coefficient, which is insignificant in both models.

The targeting problem discussed in the previous section is borne out in the results when we compare the estimated elasticities of the price coefficients between the two models: nutrient prices target the source of the nutrient impact on BMI better than do food group prices. Based on statistical significance, the nutrient price model is superior to the food group price model, since the price of carbohydrates, the price of protein and the price of fat are highly statistically significant. This is in contrast to the food group price model where, of the nine food group prices included in the model, only three, the price of eggs, the price of fats and oils and the price of restaurant food are statistically significant.

The results point out the dangers of using group price elasticities in the place of nutrient elasticities when making judgements concerning the effect of public policies on food outcomes. For example, Gray et al. (2005) use 
Tab. 2: OLS Estimates of double log specification of the BMI of Canadians, 2010

\begin{tabular}{|c|c|c|c|c|c|}
\hline \multirow[b]{2}{*}{ Regressor } & \multicolumn{2}{|c|}{$\begin{array}{c}\text { Food Group Price } \\
\text { Model }\end{array}$} & \multicolumn{2}{|c|}{ Nutrient Price Model } & \multirow[b]{2}{*}{ Regressor* } \\
\hline & Estimate & t-value & Estimate & t-value & \\
\hline Intercept & 2.736 & 33.902 & 2.782 & 79.792 & \\
\hline Age & 0.039 & 10.831 & 0.038 & 10.475 & \\
\hline Gender (Male = 1) & 0.042 & 23.002 & 0.041 & 22.834 & \\
\hline Married $($ Yes = 1) & 0.018 & 6.048 & 0.020 & 6.481 & \\
\hline Common Law $($ Yes = 1) & 0.015 & 4.387 & 0.014 & 4.064 & \\
\hline Divorced (Yes = 1) & 0.003 & 0.816 & 0.003 & 0.918 & \\
\hline Household Size & 0.000 & 0.177 & 0.001 & 0.271 & \\
\hline Education & -0.021 & -3.846 & -0.023 & -4.363 & \\
\hline Has Job & 0.027 & 11.201 & 0.027 & 11.414 & \\
\hline Income & 0.006 & 3.550 & 0.006 & 3.459 & \\
\hline Self per. health ( $5=$ very unhealthy) & 0.064 & 30.078 & 0.064 & 30.160 & \\
\hline Has Asthma (Yes = 1) & 0.030 & 9.500 & 0.030 & 9.433 & \\
\hline Has Arthritis (Yes $=1$ ) & 0.027 & 10.696 & 0.028 & 11.104 & \\
\hline Has High Blood Pressure (Yes = 1) & 0.070 & 28.357 & 0.071 & 28.549 & \\
\hline Has Diabetes $($ Yes $=1)$ & 0.087 & 24.094 & 0.087 & 24.190 & \\
\hline Has Heart Disease (Yes $=1)$ & -0.015 & -3.598 & -0.015 & -3.541 & \\
\hline Has Cancer (Yes = 1) & -0.028 & -4.597 & -0.028 & -4.626 & \\
\hline Dairy Price & -2.207 & -1.004 & -0.369 & -11.923 & Fat Price \\
\hline Fruits \& Vegetables Price & -0.136 & -0.337 & -0.214 & -10.359 & Carb. Price \\
\hline Red Meats Price & 0.412 & 0.634 & 0.608 & 12.339 & Protein Price \\
\hline Egg Price & -2.262 & -4.320 & & & \\
\hline Cereals Price & -0.464 & -1.290 & & & \\
\hline Poultry Price & -2.567 & -1.782 & & & \\
\hline Fish Price & 0.243 & 0.483 & & & \\
\hline Sugar \& Sweeteners Price & -0.521 & -1.775 & & & \\
\hline Fats \& Oils Price & 1.629 & 2.359 & & & \\
\hline Restaurant Food Price & -0.647 & -2.845 & & & \\
\hline $\mathrm{R}^{2}$ & 0.143 & & 0.140 & & \\
\hline F-Statistic & 255.100 & & 339.800 & & \\
\hline
\end{tabular}

Note: *If different than food group price model. 
an at-home food expenditure elasticity of butter, which is a developed from a sub-utility analysis of the fats and oils category taken from Goddard and Amuah (1989), in place of a fat elasticity of dairy fat to analyze the impact the Canadian Milk Marketing Board on the incidence of heart disease on Canadians. The Goddard and Amuah (1989) study did not consider the kinds of cross food group substitutions the consumers can make when they buy food from supermarkets, transport it to their homes and combine it with other foods to produce meals and food waste. If the health outcome were obesity rather than heart disease, the closest elasticity presented in Tab. 2 to that used by Gray et al. (2005) would be to use that elasticity on fats and oils price (1.629) in place of the fat price elasticity $(-0.369)$ for public policy purposes. One can see that the two bear no resemblance to one another. In addition, these elasticities only consider at-home consumption of fats and oils, and not away-from-home consumption of fats and oils.

While the fats and oils elasticity estimate seems nonsensical (since it is positive and would imply a thin subsidy be placed on this food group), it may not be so absurd when one considers what this elasticity actually measures. The "fats and oils" category includes products like vegetable oils used in salads. Lowering the price of fats and oils could potentially lead to an increase in the purchases of vegetables as consumers eat more salads, leading to a reduction in BMI. This would mean that caloric intake, which increases with the reduction in the fats and oils price, is more than offset by a reduction in caloric intake with the increase the consumption of salads, especially if the increase in the consumption of salads decreases the consumption of, say, French fries.

The ambiguity and confounded nature of nutrients associated with the use of food group prices in the reduced form model is demonstrated in the 2nd and 3rd columns of Tab. 2. Negative coefficients are indicated for prices of dairy, fruits and vegetables, cereals, eggs, sugar and sweeteners, and restaurant food. However, only the eggs and restaurant price coefficients are statistically significant. A negative coefficient indicates that a tax on the food group should be effective in reducing $\mathrm{BMI}$ and this result seems counterintuitive for fruits and vegetables, cereals and poultry.
The BMI-dairy price relationship is elastic with an estimate of -2.20 , but not statistically significant. The negative coefficient on poultry price is unexpected, given that many nutritionists have suggested that white meats are superior to red meats in promoting lower BMI. Taxing eggs would appear to be an effective way to reduce the BMI of Canadians, with an elasticity estimate of -2.26 and this result also seems counterintuitive given that eggs have been identified as a good source of protein. The coefficient on sugar \& sweeteners suggests inelasticity and a statistically insignificant impact on the BMI of Canadians, indicating a tax on this food group would have a small or negligible impact on reducing the BMI of Canadians. The restaurant price coefficient is inelastic and statistically significant indicating a tax on away-from-home food would reduce the BMI of Canadians.

Food group price coefficients with a positive coefficient include red meats, fish and fats and oils, with fats and oils have the only statistically significant coefficient of 1.629 . This conclusion seems unreasonable but is a good example of why estimates coming from food group price as the basis for imposing taxes or subsidies may not be a good guide for public policy.

Elasticity estimates and t-values of nutrient prices are presented in columns 3 and 4 of Tab. 2 respectively. Two obesogenic (fat and carbohydrates) and one leptogenic (protein) nutrient are included in the model. Both fat and carbohydrates elasticities are negative and statistically significant, indicating they are obesogenic nutrients. Protein is positive and statistically significant, indicating a leptogenic nutrient. These results are consistent with a priori expectations. These results are also consistent with the model of Chen et al. (2002) who found that nutrient prices more accurately reflect the price of nutrients in the diets of consumers as they relate to obesity than do food group prices.

\section{Discussion and Policy Implications for Actual and Potential Food Taxes}

The results highlight the problem with using food group price elasticity estimates coming from a reduced form model of obesity. Many of the food group price coefficients are statistically insignificant. The results are consistent with a small but growing empirical literature that 
studies the effect of prices on obesity: nutrient prices target the underlying nutritional factors the affect the BMI of Canadians more accurately than do food group prices.

The results of the nutrient price model are far more plausible to assess public policy on obesity taxes. Either a tax on the fat or carbohydrate content of food or a subsidy on the protein content of food would reduce the obesity of Canadians; however, the elasticity estimates are small. The nutrient price information could also be used to impose a nutrient index tax on food, with the weights of this tax being 0.607 on fat, 0.352 on carbohydrates and -1 on protein (normalizing by the protein elasticity).

The results indicate that taxes on restaurant food would reduce the BMI of Canadians. Given that restaurant food is subject to sales taxes, the results indicate that existing taxes are an effective means to reduce the BMI of Canadians. Inasmuch as the price of restaurant food is a good proxy for "fast food" these results support those who advocate a "fat" tax on fast food as an effective method to reduce obesity in Canadians. However, the estimate is inelastic, indicating that this effect is small and there could be substantial nutritional confounding underlying the estimate that make it an unreliable as a guide to policy without some further elaboration concerning the nutritional link between which foods that are "fast" are obesogenic and not leptogenic.

The coefficients on the egg price, poultry price, and dairy price serve as a guide to the impact of implicit food taxes from supplymanaged industries. The table indicates that taxes on eggs are an effective means of reducing the BMI of Canadians and the effect is both statistically significant and elastic. This result is also true of the implicit tax on poultry from supply management although this result is statistically insignificant. Both of these results are contrary to popular perception, where egg consumption is often encouraged due to its high protein content and poultry consumption is encouraged due to its low fat content relative to other meats. This is a case of confounding which arises in the use of measures of elementary food consumption instead of meal consumption (or, even better, nutrient consumption). For example, it could be that eggs are almost always cooked using a high fat method and consumed with other high caloric foods such as bread, potatoes, and red meats. One could think of similar confounding for poultry-meat based meals reflected in the estimated poultry price elasticity.

The peculiar nature in which dairy supply management operates implies that the results of both the food group price and the nutrient price model can be used to assess the implicit taxes of the dairy supply management system. Dairy supply management allocates quota (and thus restricts supply) on the basis of the fat content of milk. This aspect of dairy supply management restricts the supply of fat in the system and increases the price of fat in food. The BMI-elasticity of fat price of -0.369 is the relevant elasticity for this policy: a fat tax is BMIreducing. The dairy supply management system also increases the price of dairy products to consumers. This would lead to a reduction of at-home dairy products purchased and the estimated elasticity of -2.207 for dairy price would suggest that this, too, would lead to a lower BMI of Canadians. However, the estimated dairy food group price elasticity is not statistically different from zero.

Recommendations related to healthy eating, for example, to eat more fresh fruits and vegetables and less fats and oils, are reflected in changing relative prices in the food group price. While this may be effective in the at-home category of food to influence dietary choices, it may not be effective for the away-from-home food category and this category is a rising proportion of consumer expenditures on food. The shift in consumer preferences towards food away-from-home means that the trade-offs in food categories represented by food pyramid prices may not help in the understanding of the rise in obesity which may be driven more by increased consumption in the away-fromhome category compared to the at-home food category.

On the other hand, the use of nutrient taxes and subsidies would presumably affect both the at-home and away-from-home categories of food purchase behavior of consumers and the behavior of producers as well, when they adjust proportions of nutrients in food when relative nutrient prices change. The preference for the use of nutrient prices in studies and nutrient taxes in practice reflects a desire to be able to more fully understand and influence the choice of food at-home versus food away-fromhome as well as the choice between raw and further-processed food at supermarkets which 
makes up an increasing proportion of storebought food of the at-home category of food. The development of nutrient prices used in this study was necessarily based on the food pyramid aggregation system and a different scheme - with less aggregation - would yield better measures of variations in nutrient prices and hence better estimates of elasticities of $\mathrm{BMI}$ with respect to nutrient prices.

There is reason to be concerned about the emphasis on at-home food purchases in studying nutrition and health outcomes with economic data. As the consumption of restaurant food increases over time, less and less of consumer behavior as it relates to health outcomes like obesity are captured in elasticity estimates related to raw food categories of the traditional at-home food groups. Empirical studies of health outcomes mostly combine price data, nutrition data, and food expenditure data. Unfortunately, most of these data are collected only for at-home food groups. Constructing expenditure share categories that include nutrients purchased away-from-home would help in generating better measures of price variation for use in empirical studies of obesity.

Taxes to improve nutrition based on food groups coming from the at-home food pyramid food groups (e.g., reducing consumption of the fat in poultry products by taxing poultry products) may be less effective in reducing obesity than an alternative tax on a food in the away-from-home food category (e.g., reducing the consumption of the fat in pizzas by taxing pizzas). If a tax were to be imposed, based on our results our preference would be to tax nutrients rather than food groups, to encourage the consumption of healthier food, including healthier pizzas and poultry products, by taxing fat and carbohydrates and subsidizing protein. In the meantime, maintaining the system of dairy supply management to restrict the quantity of fat entering Canadian diets and taxing awayfrom-home food consumption, using taxes on restaurant purchases, appear to be reasonable and feasible policy responses to the rising BMI of Canadians. There is also relatively strong evidence based on literature review. Niebylski et al. (2015) found in their comprehensive review that there is an evidence that taxation and subsidy intervention influence dietary behaviors. To order to maximize success and effect, this review suggests that food taxes and subsidies should be a minimum of $10 \%$ to $15 \%$ and preferably used simultaneously (Niebylski et al., 2015).

Across countries, current regulatory approaches to obesity prevention are limited in reach and scope. Target group is rarely the general population, but instead sub-populations in government-supported settings. Consumer information provision is preferred over taxation and marketing restrictions other than the regulation of health and nutrition claims. In the EU in particular, product reformulation with industry consent has also emerged as a popular small-scale measure (Sisnowski, Handsley, \& Street, 2015). According to Sisnowski, Handsley and Street (2015) the jurisdictional activities between 2004-2013 included nutrition labeling (informative or interpretative), food marketing (advertising or health claims), food standards (institutions or programs), product reformulation and last but not least taxation. According to their review only three EU countries introduced far-reaching legislation intended to change food purchasing behaviors in the general population by establishing special kind of taxation. Namely France in 2011 (sugar) Hungary in 2011 (e.g. sugar, caffeine, salt) and Denmark in 2011 (saturated fat content, sugar content).

Denmark introduced the world's first tax on saturated fat, but only 15 months later the fat tax was abolished (Bødker et al., 2015). Bødker et al. (2015) findings suggest that industry and trade associations were heavily involved in the political process of formulating the fat tax. Industry representatives used certain tactics to oppose the fat tax: threatening lawsuits, predicting welfare losses, casting doubt on evidence, diverting focus and requesting postponement. They found that after the fat tax was implemented, the food industry continued their opposition through intensified lobbyism and juridical actions at EU level (ibid). According to Bødker et al. (2015) other factors seem to have contributed to the fall of the fat tax. The tax received criticism for being poorly designed and gradually lost popularity among health professionals, politicians and the public.

Only country of CEE that introduced the junk food tax was Hungary. Tax on food high in salt, sugar or caffeine was introduced in Hungary in 2011 (Bíró, 2015). I tis estimated that the introduction of the tax led to decline in consumption of the processed food. Dietary habits improved due to the tax mainly among the poorer households (Bíró, 2015). 
Blecher (2015) found that increases in taxes will reduce the overall demand for tobacco, alcohol or SSBs. Increases in tax rates under a dose tax will also create further incentives for producers to lower doses. Blecher (2015) also discusses why the SSBs taxation is rather limited. Chen, Kaiser and Rickard (2015) conducted the experimental study on impact of inclusive and exclusive taxes on healthy eating. Their results indicate that an inclusive tax has a significantly stronger effect on reducing the consumption of total calories, calories from fat, and the intake of carbohydrates, cholesterol, sugar and sodium compared with an exclusive tax (see Chen, Kaiser, \& Rickard, 2015).

\section{Conclusions}

Results for nutrients indicate that taxing fat and carbohydrates and subsidizing protein would reduce $\mathrm{BMI}$. The implicit tax on fat from dairy supply management is one of the only nutrienttargeted taxes in Canada. In the alternate model, few food group price coefficients are statistically significant. We find that a tax on away-from-home food would reduce the BMI of Canadians. Currently, expenditure on restaurant meals is taxed at the federal level and at the provincial level in all provinces except Alberta and Saskatchewan. The proposed model may be also used for future discussion of the food taxation in other countries where food taxation is not used and the special taxation of restaurant food is not introduced.

The authors would like to thank the Consumer and Market Demand Research Network for support for this research: http:// www.consumerdemand.ualberta.ca/.

\section{References}

Allais, O., Bertail, P., \& Nichele, V. (2010). The effects of a fat tax on French households' purchases: A nutritional approach. American Journal of Agricultural Economics, 92(1), 228245. https://doi.org/10.1093/ajae/aap004.

Auld, M. C., \& Powell, L. M. (2009). Economics of food energy density and adolescent body weight. Economica, 76, 719-740. https://doi.org/10.1111/j.14680335.2008.00709.x.

Bíró, A. (2015). Did the junk food tax make the Hungarians eat healthier? Food Policy, 54, 107-115. https://doi.org/10.1016/j. foodpol.2015.05.003.
Beatty, T. K. M., \& LaFrance, J. T. (2005). United States demand for food and nutrition in the twentieth century. American Journal of Agricultural Economics, 87(5), 1159-1166. https://doi.org/10.1111/j.14678276.2005.00802.x.

Beatty, T. K. M. (2007). Recovering the shadow value of nutrients. American Journal of Agricultural Economics, 89(1), 52-62. https://doi.org/10.1111/j.1467-8276.2007.00962.x.

Bender, A. D. (2008). Introduction to Nutrition and Metabolism (4th ed.). Boca Raton, Florida: CRC Press, Taylor \& Francis Group.

Blecher, E. (2015). Taxes on tobacco, alcohol and sugar sweetened beverages: Linkages and lessons learned. Social Science \& Medicine, 136, 175-179. https://doi.org/10. 1016/j.socscimed.2015.05.022.

Boizot-Szantai, C., \& Fabrice, E. (2005). The food prices/body mass index relationship: Theory and evidence from a sample of French adults. In 11th Congress of the European Association of Agricultural Economists, August, 2005. Retrieved October 7, 2017, from http://purl.umn.edu/24734.

Bødker, M., Pisinger, C., Toft, U., \& Jørgensen, T. (2015). The rise and fall of the world's first fat tax. Health policy, 119(6), 737-742. https://doi.org/10.1016/j.healthpol.2015.03.003.

Cardwell, R., Lawley, C., \& Xiang, D. (2015). Milked and feathered: The regressive welfare effects of Canada's supply management regime. Canadian Public Policy, 41(1), 1-14. https://dx.doi.org/10.3138/cpp.2013-062.

Chen, S. N., Shogren, J. F., Orazem, P. F., \& Crocker, T. D. (2002). Prices and health: Identifying the effects of nutrition, exercise and medication choices on blood pressure. American Journal of Agricultural Economics, 84(4), 990-1002. https://doi.org/10.1111/14678276.00362.

Chen, X., Kaiser, H. M., \& Rickard, B. J. (2015). The impacts of inclusive and exclusive taxes on healthy eating: An experimental study. Food policy, 56, 13-24. https://doi.org/10.1016/j. foodpol.2015.07.006.

Centers for Disease Control and Prevention. (2015). Obesity and overweight. Retrieved October 5, 2017, from http://www.cdc.gov/nchs/ fastats/obesity-overweight.htm.

Chou, S.-Y, Grossman, M., \& Saffer, H. (2004). An economic analysis of adult obesity: Results from the behavioral risk factor surveillance system. Journal of Health 
Economics, 23(3), 565-578. https://doi. org/10.1016/j.jhealeco.2003.10.003.

Chouinard, H. H., Davis, D. E., LaFrance, J. T., \& Perloff, J. M. (2005). The Effects of a Fat Tax on Dairy Products [UC Berkeley, Working Paper Series]. UC Berkeley, Department of Agricultural \& Resource Economics. Retrieved October 5, 2017, from http://ageconsearch. umn.edu/bitstream/25078/1/wp051007.pdf.

Cranfield, J. A. L. (2007). Estimating the distribution of body mass index [CMD funded project CMD 07-08]. Consumer and Market Demand, University of Alberta. Retrieved March 26, 2014, from http://www.consumerdemand.rees. ualberta.ca/Publications/CMD\%2007-08.pdf.

Clark, J. S., \& Dittrich, O. L. (2010). Alternative fat taxes to control obesity. International Advances in Economic Research, 16(4), 388-394. https://doi.org/10.1007/s11294-010-9282-z.

Clark, J. S., Dittrich, O. L., Law, S., \& Xu, Q. (2014). Nutrient prices and other socioeconomic and health determinants of the body mass index of Canadians. International Advances in Economic Research, 20(3), 249-258. https://doi.org/10.1007/s11294-0149475-y.

Clark, J. S., \& Levedahl, W. J. (2006). Will fat taxes cause Americans to become fatter? Some evidence from US meats. In Contributed paper prepared for the presentation at the International Association of Agricultural Economists Conference, Gold Cost, Australia. Retrieved October 5, 2017, from http://ageconsearch.umn.edu/bitstream/25710/1/ cp061111.pdf.

Cutler, M. D., Glaeser, E. L., \& Shapiro, J. M. (2003). Why have Americans become more obese? [NBER Working Paper, No. 9446]. https://doi.org/10.3386/w9446.

Goddard, E. W., \& Amuah, A. K. (1989). The demand for Canadian fats and oils: A case study of advertising effectiveness. American Journal of Agricultural Economics, 71(3), 741-749. https://doi.org/10.2307/1242030.

Goldman, D., Lakdawalla, D., \& Zheng, Y. $\mathrm{H}$. (2009). Food prices and the dynamics of body weight [NBER Working Paper No. 15096]. https://doi.org/10.3386/w15096.

Gray, R., Malla, S., \& Stephen, A. (1998). Canadian dietary fat substitutions, 1955-93, and coronary heart disease costs. Canadian Journal of Agricultural Economics, 46(2), 233-246. https://doi.org/10.1111/j.1744-7976.1998. tb00365.x.
Gyles, C. L., Lenoir-Wijnkoop, I., Carlberg, J. G., Senanayake, V., Gutierrez-Ibarluzea, I., Poley, M. J., ... \& Jones, P. J. (2012). Health economics and nutrition: a review of published evidence. Nutrition Reviews, 70(12), 693-708. https://doi.org/10.1111/j.17534887.2012.00514.x.

Huang, K. (1996). Nutrient elasticities in a complete food demand system. American Journal of Agricultural Economics, 78(1), 21-29. https://doi.org/10.2307/1243775.

Lakdawalla, D., \& Philipson, T. (2002). The growth of obesity and technological change: $A$ theoretical and empirical examination [NBER Working Paper No. 8946]. https://doi. org/10.3386/w8946.

Nichols, B. L. (1994). Atwater and USDA nutrition research and service: A prologue of the past century. Journal of Nutrition, 124(9 Suppl), 1718S-1727S. https://doi.org/10.1093/jn/124. suppl_9.1718S.

Niebylski, M. L., Redburn, K. A., Duhaney, T., \& Campbell, N. R. (2015). Healthy food subsidies and unhealthy food taxation: A systematic review of the evidence. Nutrition, 31(6), 787-795. https://doi.org/10.1016/j. nut.2014.12.010.

OECD. (2017). Obesity Update 2017. Paris: OECD. Retrieved from www.oecd.org/health/ obesity-update.htm Accessed $5^{\text {th }}$ October 2017.

Raben, A., Agerholm-Larsen, L., Flint, A., Holst, J. J., \& Astrup, A. (2003). Meals with similar energy densities but rich in protein, fat, carbohydrate, or alcohol have different effects on energy expenditure and substrate metabolism but not on appetite and energy intake. The American Journal of Clinical Nutrition, 77(1), 91-100. https://doi.org/10.1093/ajcn/77.1.91.

Sisnowski, J., Handsley, E., \& Street, J. M. (2015). Regulatory approaches to obesity prevention: A systematic overview of current laws addressing diet-related risk factors in the European Union and the United States. Health Policy, 119(6), 720-731. https://doi. org/10.1016/j.healthpol.2015.04.013.

Smed, S., Jensen, J. D., \& Denver, S. (2007). Socio-economic characteristics and the effect of taxation as a health policy instrument. Food Policy, 32(5-6), 624-639. https://doi. org/10.1016/j.foodpol.2007.03.002.

Statistics Canada. (2012a). Body mass index, overweight or obese, self-reported, adult, by age group and sex. Retrieved June 10, 2013, from http://www.statcan.gc.ca/tables-tableaux/ 
sum-som/I01/cst01/health81a-eng.htm.

Statistics Canada. (2012b). Canadian Community Health Survey-Annual Component (CCHS). Retrieved September 11, 2012, from http://www23.statcan.gc.ca/imdb/p2SV. pl?Function=getSurvey $\&$ SDDS $=3226$.

Statistics Canada. (2012c). Table 0030080: Nutrients in the food supply, by source of nutritional equivalent and commodity, annual (milligrams unless otherwise noted). CANSIM (database).

Statistics Canada. (2012d). Table 203-0021: Survey of household spending (SHS), household spending, Canada, regions and provinces, annual (dollars). CANSIM (database).

Statistics Canada. (2012e). Table 2030028: Survey of household spending (SHS), food expenditures, Canada, annual (dollars). CANSIM (database).

Statistics Canada. (2012f). Table 326-0021: Consumer Price Index (CPI), 2009 basket, annual (2002=100 unless otherwise noted). CANSIM (database).

Sturm, R., \& Datar, A. (2005). Body mass index in elementary school children, metropolitan area food prices and food outlet density. Public Health, 119(12), 1059-1068. https://doi.org/10.1016/j.puhe.2005.05.007.

Sturm, R., \& Datar, A. (2008). Food prices and weight gain during elementary school: 5-year update. Public Health, 122(11), 1140-1143. https://doi.org/10.1016/j. puhe.2008.04.001.

United States Department of Agriculture, Economic Research Service. (2014). Table 10-Food away-from-home as a share of food expenditures. Retrieved March 24, 2014, from http://www.ers.usda.gov/data-products/foodexpenditures.aspx\#26636.

$\mathrm{Xu}, \mathrm{Q}$. (2011). Consumers' decisions on calories, fat, and carbohydrates with respect to food prices and expenditures (Master's thesis). Dalhousie University, Halifax.

Prof. Stephen J. Clark, Ph.D. Delhausie University

Department of Business \& Social Sciences Canada jsclark@dal.ca

Prof. Stephen M. Law, Ph.D. Departmet of Economics Mount Allison University Canada slaw@mta.ca

PhDr. Ludwig O. Dittrich, Ph.D. Czech University of Life Sciences Prague Department of Economic Theories Czech Republic dittrich@pef.czu.cz

Ing. Dana Stará, Ph.D. Czech University of Life Sciences Prague Department of Economic Theories

Czech Republic starad@pef.czu.cz

PhDr. Miroslav Barták, Ph.D. J. E. Purkyně University in Ústí nad Labem Faculty of Social and Economic Studies Department of Social Work Czech Republic miroslav.bartak@ujep.cz 


\title{
Abstract
}

\section{FOOD PRICES, TAXES, AND OBESITY IN CANADA AND ITS IMPLICATIONS FOR FOOD TAXATION}

\author{
Stephen J. Clark, Ludwig O. Dittrich, Stephen M. Law, Dana Stará, \\ Miroslav Barták
}

An important health financing issue facing Canada and other OECD countries are the health consequences of obesity. Food group prices can be used to estimate the model if one is interested in a reduced form model of the determinants of obesity and nutrient prices should be used if one is interested in estimating a structural model of obesity that is more amenable to interpretation for policy purposes. The goal of the study is to introduce new nutrient price model and shows its superiority of food group model based on Canadian data Using available data from the Canadian Community Health Survey, food group prices, and constructed nutrient indexes, we confirm the superior performance of variations in nutrient prices compared to variations in food group prices to explain variations in the body mass index (BMI) of Canadians. Results for nutrients indicate that taxing fat and carbohydrates and subsidizing protein would reduce BMI. The implicit tax on fat from dairy supply management is one of the only nutrient-targeted taxes in Canada. In the alternate model, few food group price coefficients are statistically significant. We find that a tax on away-fromhome food would reduce the BMI of Canadians. Currently, expenditure on restaurant meals is taxed at the federal level and at the provincial level in all provinces except Alberta and Saskatchewan. The proposed model may be also used for future discussion of the food taxation in other countries where food taxation is not used and the special taxation of restaurant food is not introduced.

Key Words: Goods and services tax, sales tax, supply management, BMI, obesity, nutrient prices.

JEL Classification: H21, I12, I18.

DOI: 10.15240/tul/001/2019-1-002 